\title{
Uma "monstra perigosa": Pistas de Carolina Maria de Jesus para a intervenção psicossocial
}

Érika Cecília Soares Oliveira. Universidade Federal de Alagoas

\section{Resumo}

Este artigo toma como pressuposto que a atuação profissional em psicologia deve ter claramente um compromisso ético-político, algo que ainda não se vê com contundência, sobretudo a partir de relatos que demonstram a experiência de psicóloga(o)s em instituições públicas e sua permanência em modelos tradicionais de intervenção. Seu objetivo principal é colocar em evidência debates que considerem os modos de vida dos diferentes grupos sociais, a fim de produzir articulações entre os múltiplos marcadores sociais das diferenças que, por vezes, os constituem. Para tanto, trago um livro de Carolina Maria de Jesus - Quarto de despejo: diário de uma favelada - como possibilidade de construir diálogos transdisciplinares a respeito de eixos de poder e diferenciação, aproximando-me de seu território existencial a fim de compreender o modo como essa escritora produz conhecimento sobre sua realidade. Trata-se de propor um exercício que coloque em relevo a complexidade dos sujeitos para os quais direcionamos nossas intervenções psicossociais. Palavras-chave: marcadores sociais das diferenças; desigualdade social; intervenção psicossocial; feminismos; Carolina Maria de Jesus.

\section{Abstract}

A "dangerous female monster": Carolina Maria de Jesus' clues to the psychosocial intervention. This article starts from the assumption that the professional actuation in psychology must clearly have an ethical-political commitment, something that is not strongly seen yet, especially from relates that demonstrate the experience of psychologists in public institutions and their permanence on traditional models of intervention. Its main objective is to put in evidence debates that consider the ways of life of different social groups, so as to produce articulations among the multiple social markers of the differences that sometimes constitute them. For that, I suggest a book by Carolina Maria de Jesus - Child of the Dark: the Diary of Carolina Maria de Jesus (Quarto de Despejo: Diário de uma Favelada) - as a possibility of constructing transdisciplinary dialogues about axes of power and differentiation, approaching her existential territory in order to comprehend the way that writer produces knowledge of her reality. It is a question of proposing an exercise that highlights the complexity of the individuals to whom we address our psychosocial interventions.

Keywords: social markers of differences; social inequality; psychosocial intervention; feminisms; Carolina Maria de Jesus.

\section{Resumen}

Una "monstrua peligrosa": Pistas de Carolina Maria de Jesus para la intervención psicosocial. Este artículo tiene como presupuesto que la actuación profesional en la psicología debe tener un principio ético-político claro, lo que aún no se ve explícitamente, sobre todo a partir de relatos que demuestran la experiencia de psicólogos(as) en instituciones públicas y la actuación basada en los modelos tradicionales de intervención. Su objetivo principal es evidenciar debates que consideren los modos de vida de los diferentes grupos sociales, para que se produzcan relaciones entre los múltiplos marcadores sociales de las diferencias que, muchas veces, los constituyen. Para tanto, traigo un libro de Carolina Maria de Jesus - Quarto de despejo: diario de uma favelada [Cuarto trastero: diario de una chabolista] - como una posibilidad de construir diálogos transdisciplinarios a respecto de ejes de poder y diferenciación, aproximándome de su territorio existencial con el fin de comprender el modo como esa escritora produce conocimientos sobre su realidad. Se trata de proponer un ejercicio que destaque la complejidad de los sujetos para quienes direccionamos nuestras intervenciones psicosociales.

Palabras clave: marcadores sociales de las diferencias; desigualdad social; intervención psicosocial; feminismos; Carolina Maria de Jesus. 
Muito se tem dito sobre a necessidade de que a formação em psicologia esteja preparando suas(seus) estudantes para uma prática que dê conta da realidade social, permitindo que sejam formada(o)s levando em consideração a transformação dessa mesma realidade. A crescente inserção de psicóloga(o)s em campos como a saúde pública e assistência social, embora seja algo recente em nossa prática profissional, tem demonstrado a extrema necessidade de nos exercitarmos cotidianamente para repensarmos com quais pressupostos teóricos, metodológicos e epistemológicos operacionalizamos essa prática. De acordo com Yamamoto e Oliveira (2010), ainda que tal inserção ganhe cada vez mais contornos nítidos, ela não é acompanhada de significativas modificações nos paradigmas que orientam a formação em psicologia, o que acaba refletindo no quefazer de profissionais inserida(o)s nos mais variados serviços. Somam-se a essa constatação inúmeras vozes de autoras e autores que, por meio de suas investigações, lançam luz sobre os modos de trabalhar de psicóloga(o)s em diferentes áreas como a saúde (Dimenstein \& Macedo, 2012), a assistência (Cruz, 2009) e também em lugares, como as instituições e serviços voltados para o enfrentamento das violências de gênero (Hanada, D'Oliveira, \& Schraiber, 2010). El(a)es apontam para o fato de que, na maioria das vezes, a(o) psicóloga(o) encontra-se aprisionada(o) numa perspectiva clínica tradicional, mesmo quando é levada(o) a trabalhar em equipes que a(o) obrigam, de algum modo, a inaugurar outros espaços de atuação, a desenvolver atividades diferenciadas quando comparadas às psicoterapias (individuais ou grupais) usualmente utilizadas. Ainda que colocada(o) a atuar em situações que exigem o trabalho coletivo e a quebra do modelo clínico tradicional, isso costuma provocar ambiguidades, como se essas outras atividades não descrevessem, necessariamente, aquilo que é esperado do saber técnico aprendido durante os anos de formação universitária, o que coloca em relevo os limites da ciência psicológica e da formação de suas(seus) profissionais (Yamamoto \& Oliveira, 2010).

Ao analisar a relação entre políticas públicas e práticas de profissionais da saúde voltadas para o enfrentamento da violência contra as mulheres, Schraiber (2012) coloca uma questão extremamente importante: a autora parte do pressuposto de que as práticas profissionais devem ser definidas através de determinantes técnico-científicos e sócio-históricos que delimitam a produção social de um trabalho, chamando a atenção para o fato de que existem grandes dificuldades para executá-las, em razão de uma série de obstáculos (culturais e político-ideológicos). Isso, por sua vez, acaba por afetar a operacionalização das políticas públicas, já que as mesmas, para que aconteçam no cotidiano dos serviços, são desenvolvidas por profissionais responsáveis por executá-las. É justamente a politização da intervenção técnico-científica que auxiliará na quebra dos obstáculos para o desempenho efetivo de tais políticas. Ao tomar como exemplo o aborto legal, ela verifica que embora seja uma ação prevista em casos de estupro, há grande dificuldade de realizá-lo no plano das práticas profissionais justamente porque essas são desempenhadas baseadas em crenças, julgamentos morais e bases religiosas de caráter exclusivamente pessoal. Com isso, ela faz uma distinção entre políticas públicas e práticas profissionais e coloca em relevo a dependência das primeiras em relação as segundas dentro das instituições. Embora a autora esteja falando estritamente de profissionais de saúde e de violência de gênero, acredito que seja possível transferir suas reflexões para pensarmos a formação e a prática da psicologia. Montero (2006; 2015) ao falar do trabalho psicossocial comunitário discorre sobre um agir profissional politizado que tenha como diretriz o desenvolvimento do controle e do poder de atrizes e atores sociais de modo que possam realizar mudanças em seu entorno e, consequentemente, na estrutura social. Isso remete, portanto, à necessidade de levar os sujeitos a analisarem criticamente as circunstâncias de sua vida. A ideia é que tais atrizes e atores possam abandonar o papel de receptora(e)s passiva(o)s de políticas públicas que não necessariamente lhes são adequadas (muitas vezes, elas são francamente errôneas, segundo essa autora), de modo que possam planejar aspectos da vida pública que lhes dizem respeito.

O contexto social contemporâneo brasileiro e a abertura de instituições de caráter público para profissionais da psicologia têm colocado como questão a necessidade de pensarmos esse momento específico de modo a garantir que sua complexidade seja considerada quando do exercício profissional. De acordo com Mayorga (2014), o momento atual difere do período de 1960-1970, em que a psicologia social trazia questões relacionadas exclusivamente à classe social para pensar o momento de extrema desigualdade social pela qual o Brasil passava, baseada na influência do marxismo que referendou parte significativa das leituras daquele período. Hoje em dia, os debates sobre desigualdade social não podem ser apartados de discussões que 
considerem eixos de diferenciação e poder como raça, etnia, sexualidade, gênero, orientação sexual, nacionalidade, dentre outros. A perspectiva interseccional trazida pelos feminismos das diferenças da década de 1980 tem sido a contribuição das teorizações feministas pós-coloniais para a psicologia social comunitária repensar suas práticas e intervenções de modo a colocar em relevo as vozes das novas atrizes e atores sociais que estão emergindo. Esse é o momento, portanto, de se considerar que as opressões e desigualdades afetam mulheres, população LGBT, negras e negros, minorias étnicas, de modo diferenciando, exigindo, assim, uma ampliação em nossas leituras a respeito dos elementos psicossociais de opressão, dominação e também daqueles responsáveis por movimentos de emancipação (Mayorga, 2014).

Para isso, é preciso que críticas sejam feitas em relação ao "sujeito psicológico" descolado da realidade e que ainda vigora de modo contundente na prática da psicologia (Dimenstein, 2000). Neste caso, os sujeitos devem ser pensados, como nos ensina Milton Santos (2012) dentro de um país, de uma realidade social e, para se compreender os eixos de poder que constituem suas identidades e que constroem diferenças, devem também ser considerados, simultaneamente, dentro de um contexto nacional e internacional (Brah, 2006) que os molda, embora eles sempre possuam condições, em determinadas circunstâncias, de escapar ou causar ranhuras nas contingências que os configuram.

A psicologia social, ao longo de sua história, passou a interessar-se pela multiplicidade do cotidiano (Jacó-Vilela, 2007), o que levou-a a construir uma série de teorias, práticas e metodologias para compreendê-lo, levando-nos a falar em psicologias sociais no plural. As perguntas que ainda pontuam esse campo dizem respeito ao modo como a(o)s profissionais da psicologia devem ser preparada(o)s de modo a atuarem de maneira comprometida com a realidade social e também para ultrapassarem os modelos e paradigmas tradicionais (Freitas, 2015). Os cinquenta anos de regulação da profissão mostram que essas questões ainda são extremamente atuais, dado que nem sempre se tem evidenciado o compromisso ético-político desse campo de conhecimento (Antunes, 2012).

Nesse artigo, defendo que a perspectiva interseccional interessa não apenas a uma parcela da psicologia (a saber, as feministas), chamando a atenção também para a ideia de que a psicologia social não deveria ser reduzida a uma disciplina, uma especialidade dentro da psicologia (Stralen, 2005). Pelo contrário, toda psicologia deve estar interessada em enfrentar as desigualdades, rompendo com pressupostos que isolam o indivíduo, psicologizando suas experiências, apartando-o de seus processos de subjetivação. Na narrativa autobiográfica de Azerêdo (2003) em "Era uma vez... uma análise", essa autora conta como foi sua experiência como paciente de um analista que compreendia que ela deveria deixar de ser feminista e tornar-se feminina. Ela aponta para o fato de que o analista em questão sempre tinha uma teoria pronta sobre ela, obrigando-a a se encaixar nela, não estando preparado, portanto, para questionar visões tradicionais do que era ser mulher. Ao longo do relato de Azerêdo (2003), é possível identificar como uma prática que desconsidera os marcadores sociais das diferenças e as desigualdades sociais e que trabalha com sujeitos universais, a-históricos e essencializados, não apenas reproduz estereótipos e atos performativos altamente rígidos, como também é responsável por cometer violências em nome de um saber técnico pretensamente neutro. Acredito que seja a esse tipo de fazer que Mayorga (2014) se refere quando nos adverte sobre o risco de transformarmos nossa prática em um tecnicismo reducionista cujos efeitos levam à neutralização dos conflitos sociais e despolitização da realidade. Ao contrário dessa prática, o que é necessário realizar e que exige um olhar complexo sobre o fazer em psicologia é justamente o que Gonçalves Filho (2003) diz: tratar os sofrimentos levando em consideração as múltiplas facetas do mesmo. Nas palavras dele: "Não é frutífero que sofrimentos políticos sejam apenas politicamente enfrentados, uma vez que são sofrimentos. E não é frutífero que sofrimentos políticos sejam apenas psicologicamente enfrentados, uma vez que são políticos" (Gonçalves Filho, 2003, p. 219). Essa perspectiva, como é possível observar, não tolera os reducionismos e psicologismos tão caros à nossa formação. Fico, portanto, com a ideia trazida por esse autor de que é necessário realizar um deslocamento em nossas intervenções a fim de olhar a opressão perto daquela(e)s que são oprimi$\mathrm{da}(\mathrm{o}) \mathrm{s}$ e, sobretudo, imaginando-se no lugar dela(e)s. Este seria um "[...] compromisso interior e de trabalho ombro a ombro" (Gonçalves Filho, 2003, p. 196).

O convite que faço agora é que, a partir de uma experiência que transita entre psicologia e obra literária, passemos a fazer coro às vozes de autora(e)s que já têm chamado a atenção para que nosso olhar encare os processos psicossociais de modo mais amplificado, deixando para trás as vistas curtas que toda tradição científica traz quando do momento de sua constituição. Levando as 
discussões trazidas pelo feminismo das diferenças para a minha prática profissional, há quatro anos tive oportunidade de entrar em contato com a obra de Carolina Maria de Jesus - "Quarto de despejo: diário de uma favelada" - o que permitiu-me, a partir daí, ilustrar a complexidade da categoria mulher justamente porque há uma multiplicidade delas, com experiências plurais, que não podem ser reduzidas a uma única voz e, consequentemente, a uma única intervenção ou atuação profissional. Trata-se de um exercício de interrogar a própria prática, a partir da afirmação de um fazer transdisciplinar que nega guetos, verdades absolutas, universais (Coimbra, 2007) e que venho realizando a partir de disciplinas ministradas e pesquisa de projeto de iniciação científica em uma universidade federal que tomam esta autora como leitura obrigatória ${ }^{1}$.

Carolina Maria de Jesus (1914²-1977) nasceu em Sacramento, cidade do interior de Minas Gerais. Ela mora com sua mãe, tem uma infância extremamente pobre, trabalha na roça e depois como empregada doméstica. Aos 23 anos migra para São Paulo, volta a trabalhar como doméstica e passa a morar em cortiços. Em 1948, muda-se para a favela do Canindé, às margens do Rio Tietê. A atividade laboral que Carolina mais exerce é a de catar papéis pelas ruas da cidade (Gonçalves, 2014). Em 1960 ela torna-se best seller ao lançar o livro "Quarto de despejo: diário de uma favelada", emplacando suas vendas junto com escritores como Jorge Amado (Meihy, 2016). Apesar de ter cursado dois anos de escola primária em Sacramento, Carolina escreve mais de 4.500 páginas manuscritas, em $37^{3}$ cadernos retirados das lixeiras da grande São Paulo, mostrando que a escrita para ela não era uma escolha, mas sim um destino (Gonçalves, 2014). "Quarto de despejo" é o resultado de uma edição de 20 cadernos manuscritos realizada pelo cronista e jornalista Audálio Dantas (Sousa, 2011). O livro alcança a marca de 100.000 exemplares vendidos em poucos meses, após seu lançamento, ganhando sucessivas tiragens feitas pela Editora Livraria Francisco Alves, sendo traduzido nos anos seguintes, para 14 idiomas e comercializado em mais de 40 países (Gonçalves, 2014; Pinheiro \& Barbosa, 2016), destacando-se, ainda hoje, como um dos livros brasileiros mais conhecidos de todos os tempos (Meihy, 2016). Este livro revela uma escrita cotidiana, que segue o ritmo dos dias, coincidindo, de acordo com Gonçalves (2014), com a construção e elaboração da história de seu sofrimento cujo cenário é a favela e cuja protagonista é a fome, a qual Carolina acredita ser amarela, assim como o governo que não ouve suas reclamações, os serviços públicos, o juizado de menores, a enfermidade, a pobreza (Querido,
2012). Carolina escreve poemas, provérbios, peças de radionovela, romances, muitos deles ainda inéditos. Sua obra é demarcada por Meihy (2016) a partir de um antes e um depois do golpe militar de 1964. Compreendida como subversiva por levar a público as mazelas da legião de pobres da metrópole, a escritora é sutilmente tirada de cena com a instalação da ditadura.

As obras de Carolina têm muito a nos ensinar quando o assunto é desigualdade social e marcadores sociais das diferenças e, nesse artigo, coloco em foco o primeiro livro lançado por ela, "Quarto de despejo". Para a perspectiva que ora apresento encarar processos psicossociais de modo mais abrangente, ao conhecer a vida e obra dessa mulher, teria a ver com ampliar o campo de debates da psicologia, produzindo diálogos transdisciplinares e também em problematizar sobre quem tem direito de produzir explicações a respeito do mundo. Nas palavras de Gonçalves (2014, p. 25): "Seu 'estranho diário' é um modo visceral de tomada de consciência de si e dos outros, de sua cor da pele, do cenário em que vive e pelo qual deambula pelas ruas de São Paulo à cata de papel [...]". A inferiorização dos conhecimentos produzidos por mulheres e homens de todo o planeta tem dotado 'homens' ocidentais do privilégio epistêmico de definir o que é verdade, o que é a realidade e o que é melhor para os demais e esta tem sido a marca das universidades ocidentalizadas, de acordo com Grosfoguel (2016). É justamente isso que é preciso colocar sob suspeita. A psicologia deve implicar-se com descolonizações epistêmicas a fim de repensar suas teorias, problemas de pesquisa, intervenções, práticas, autora(e)s. A descolonização tem a ver com a tentativa de realizar uma operação que consistiria em se desapegar do eurocentrismo e abrir-se para outras experiências, histórias e teorias que são costumeiramente tornadas menores, abjetas, desqualificadas (Gomes, 2015). De acordo com Gomes (2015), devemos fustigar a pedagogia que preconiza a simples adesão ao cânone. Para tanto, é preciso revisar e torcer silêncios produzidos por teorias do Norte Global que se pretendem universais. Conhecimentos produzidos nas margens acabam por afetar a própria textura do pensamento, de acordo com este autor, de modo que a pergunta que se faz é: e se buscarmos outras formas de ser e de pensar nossa realidade, outras cosmovisões? A fricção de teorias-outras com a psicologia serve para desmanchar fronteiras e territórios cristalizados, percorrendo outras prateleiras. Essas prateleiras apontam para o fato de que, ao contrário do que a ciência hegemônica do Ocidente tem pregado, as práticas sociais estão engendrando domínios de saber que fazem 
aparecer novos objetos, novos conceitos, novas técnicas, novas formas de sujeitos do conhecimento, como bem demonstra Coimbra (2007).

Por isso, nesse trabalho Carolina será compreendida como sujeito do conhecimento capaz de criar categorias próprias, sendo protagonista de sua história a partir de sua própria experiência. A leitura de seu texto serve para repensarmos o modo como produzimos conhecimento bem como a complexidade dos sujeitos que são atendidos em nossas intervenções psicossociais nas diversas instituições destinadas a essa finalidade. Com isso, quero demonstrar que, embora a fome figurasse como uma das personagens principais dessa obra, Carolina tinha muito a dizer e ensinar, seguindo a linha que Anzaldúa (2000, p. 235) definiu muito bem: "Mesmo se estivermos famintas, não somos pobres de experiências".

\section{Escrevendo com o Próprio Corpo}

Ao questionar se existe uma única história do feminismo, Ella Shohat (Maluf \& Costa, 2001), insere uma crítica à narrativa-mestra linear de como o feminismo começou, na qual as "outras" mulheres eram suprimidas, sendo desqualificadas como feministas por não usarem esse rótulo. Cardoso (2014) refere-se a essas mulheres como "periféricas de dentro". Como campo de poder e disputas, os feminismos muitas vezes se valem de um olhar eurocêntrico e salvacionista que tudo sabe sobre o mundo "atrasado", como aponta Preciado em entrevista a Carrillo (2010). O final da década de 1980 provoca uma ruptura nas teorizações realizadas por mulheres brancas, heterossexuais, anglófonas, protestantes e de classe média. Nesse período é construído o conceito de diferença, que compõe boa parte da teoria feminista multicultural sobre gênero nos Estados Unidos (Pelúcio, 2012). Nele, realiza-se uma crítica frontal ao feminismo gestado no centro, denunciando as tendências etnocêntricas e imperialistas dos feminismos europeus e americanos. As feministas buscavam estratégias epistemológicas que abarcassem as experiências vividas por mulheres consideradas as "outras" (negras, lésbicas, terceiromundistas, asiáticas, periféricas). As mulheres de cor norteamericanas, por exemplo, mostravam que no patriarcado branco norte-americano, as mulheres livres eram trocadas num sistema que as oprimia, mas nesse mesmo sistema, se fossem brancas, tais mulheres herdavam homens e mulheres negra(o)s (Haraway, 2004).

De acordo com Haraway (2004), é inestimável a contribuição das discussões feitas por mulheres não brancas na década de 1980, pois elas propuseram uma linguagem que estivesse atenta às relações de poder presentes na sociedade. A partir dessa contribuição, o feminismo sai de sua estrutura binária, que privilegia a diferença sexual, abrindo espaço para considerar as diferenças múltiplas entre as mulheres, dentro de uma abordagem interseccional que acaba por expandir o conceito de gênero. Revelava-se, com isso, que o feminismo centrado exclusivamente no gênero ou na diferença sexual não era suficiente para explicar as contradições vividas por mulheres. Para Preciado (Carrillo, 2010), o discurso dos anos 1990, pós-feminista, deu um giro conceitual na teoria feminista a partir da ideia de produção transversal das diferenças e interseccionalidade política de todos os pontos de estratificação da opressão.

Desse debate nascem tensões epistemológicas que recaem sobre conceitos estruturantes do feminismo branco, tal como a validade teórico-político da categoria mulher, levando à questão sobre quem era o sujeito do feminismo. Vê-se, portanto, que era impossível falar sobre uma mulher universal. Ao contrário disso, o que existiam eram mulheres com uma infinidade de experiências, opressões, narrativas. Uma das pioneiras na discussão sobre interseccionalidade, Kimberlé Crenshaw, mostrava como as opressões deveriam ser pensadas de modo interativo, ao invés de sobrepostas. Crenshaw (2002) trazia a ideia de diversas avenidas nas quais, em cada uma, circulam eixos de opressão que se cruzarão em determinados lugares, demonstrando que uma série de violações de direitos humanos podem ficar obscurecidas caso não sejam consideradas as interseccionalidades das vulnerabilidades de mulheres e homens marginaliza$\mathrm{da}(\mathrm{o}) \mathrm{s}$. Desse modo, ela chama a atenção para o fato de que não é possível estudar desigualdade social articulando-a somente à raça e desconsiderando suas implicações com gênero e outros marcadores (assim como também não é possível estudar gênero invisibilizando raça). Um olhar que considera os cruzamentos desses marcadores ao longo das avenidas é estratégico se quisermos não tratar de forma simplista as opressões que os grupos sociais vivenciam em seu cotidiano.

É também desse período o texto escrito pela teórica feminista Gloria Anzaldúa "Falando em línguas: carta às mulheres terceiromundistas". Sentada diante de sua máquina de escrever, ela dirige-se às mulheres negras, chicanas, índias, asiático-americanas, lésbicas, mães solteiras que arrastam-se por todas as direções, entre as obrigações com suas crianças, amantes, ex-maridos e a escrita. Anzaldúa (2000) vence em si mesma 
a barreira para começar a escrever, ela, uma "pobre chicanita do fim do mundo" (Anzaldúa, 2000, p. 230) que precisa vencer os obstáculos impostos pela escrita masculinista e pseudo-intelectual aprendida nos espaços de ensino.

Escrever para Anzaldúa (2000) era uma espécie de atrevimento. Sua linguagem marcada por classe e etnia havia sofrido um profundo apagamento desde a época em que era uma estudante, com suas(seus) professora(e)s penalizando-a quando falava em espanhol. Depois, nas plantações de tomate em que trabaIhava, suas mãos inchadas de calor e calejadas demais para segurar a pena mostravam que escrever era uma tarefa que havia sido proibida para mulheres como ela. Tais mulheres têm sido combatidas e representadas como "monstras perigosas" justamente por desequilibrarem e romperem as imagens estereotipadas que o(a)s branca(o)s possuem delas. Ao escreverem, elas podem vomitar de volta a culpa, a auto-recusa e o ódio racial que possuem e que estão voltados contra si mesmas porque as criaturas brancas as obrigam a engoli-los à força. Sua escrita, desse modo, é uma convocação às mulheres, pois parte do princípio de que uma mulher que escreve tem poder e, por isso mesmo, é temida. Por isso mesmo, ela pede para que as mulheres percam o medo de escrever e parte de sua própria experiência pessoal, do medo que sente da caneta, de sua tinta, das verdades trazidas por ela, que a impedem, tantas vezes, de fazê-lo. Escrever é um ato de resistência pelo qual se deve lutar a despeito das dificuldades. Deve-se, para tanto, sugar o sangue vital da própria experiência e derramá-lo sobre a tinta da caneta. Para tanto, as mulheres devem esquecer-se da ideia de que devem ter um local apropriado para exercitar a escrita, devendo fazê-lo em qualquer lugar: na cozinha, no banheiro, no ônibus, na fila da previdência social, no trabalho, durante as refeições, entre o dormir e o acordar, em toda parte. É preciso escrever enquanto se lava as roupas ou o chão, deixando ecoar as palavras no próprio corpo.

A partir de agora trago a escrita de Carolina Maria de Jesus que fazia justamente isso que a Anzaldúa (2000) falava em sua carta, vejam: "Eu estava escrevendo, esperando o arroz secar" (Jesus, 1960/2007, p. 109) e "- Eu preciso trabalhar e escrevo nas horas vagas" (Jesus, $1960 / 2007$, p. 175). Existem outros momentos nos quais Carolina aponta para o fato de que escrever era algo que ela fazia sempre que podia. E ela não podia sempre.

\section{Mulher, Negra, Favelada, Terceiro-Mundista, Semi- -Alfabetizada, mesmo assim, Escritora}

A vida de Carolina Maria de Jesus, sua biografia, já foi escrita em alguns livros, por isso mesmo, gostaria de deter-me no período em que a escritora mora na favela do Canindé, na cidade de São Paulo, conhece o jornalista Audálio Dantas e publica o livro "Quarto de despejo: diário de uma favelada". O nome do livro, convém lembrar, faz uma clara referência à situação de extrema desigualdade social vivenciada por milhares de brasileira(o)s naquele período e denuncia a "divisão racial do espaço", como dizia Lélia Gonzales (1984) na década de 1980, na qual pobres e negras(os) amontoam-se em cubículos, favelas, cortiços, conjuntos habitacionais. Peça fora de uso, acomodada num quarto de despejo, era assim que Carolina se via. Contraposta à "cidade", às casas de alvenaria que, para ela, pareciam o paraíso com suas mulheres e crianças bem vestidas, cheias de vasos de flores, o quarto de despejo - a favela - era, em sua opinião, a representação da enfermidade na qual se encontrava a América do Sul; sua úlcera. E ela, uma despejada, "objeto fora de uso" (Jesus, 1960/2007, p. 38). Daí o seu grande sonho era ir embora daquele lugar.

Entre 1948 e 1953 Carolina tem dois filhos e uma filha e, nesse período, constrói um barraco na proximidade da favela do Canindé, composta por mais de 150 barracões à beira do Tietê. De acordo com J. R. Santos (2009), a(o)s moradora(e)s da favela vinham atrás de algum trabalho, movida(o)s por desejos e fracassos, ciúmes, despeitos. Vinham sozinha(o)s, com filha(o)s, em grupos e eram, em sua maioria, analfabeta(o)s. O que tinham em comum era o fato de serem despossuída(o)s. Nas próprias palavras de Carolina: "... Nós somos pobres, viemos para as margens do rio. As margens do rio são os lugares do lixo e dos marginais. Gente da favela é considerado marginais". (Jesus, 1960/2007, p. 55). Carolina mora no Canindé durante quase dez anos. Nesse período, ela passa a vender papéis, vidros, estopa, metais e, muitas vezes, tem que levar a(o)s filha(o) s junto, para não deixá-la(o)s sozinha(o)s em casa. Ela vende os materiais que vai acumulando ao longo de um dia de trabalho de modo que consegue comprar alimentos para si e para as crianças, tudo isso marcado por uma grande inconstância, pois nem sempre arruma compradora(e)s. Muitas vezes, acaba tendo que valer-se de comida retirada do próprio lixo ou tem que alimentar-se de restos que encontra em um ou outro lugar.

Em 1958 Carolina encontra pela primeira vez o jornalista Audálio Dantas. Este trabalhava como repórter na Folha da Noite e fazia uma matéria na favela. Nesse 
mesmo ano ele publica uma reportagem sobre ela, apresentando-a como alguém "que vive integralmente a miséria da favela, mas se distingue dos companheiros por ser capaz de entrar em seu mundo interior sem esquecer o mundo sórdido que a cerca" (Castro \& Matta, 2007, p. 53). Conhecendo os diários escritos por Carolina, nos quais ela retratava seu cotidiano e também escrevia poesias, Audálio e seus companheiros de redação resolvem custear a edição de um deles. Em 1960, o livro "Quarto de despejo" é lançado e seu texto é definido como uma grande reportagem por denunciar fortemente a situação de miséria na qual encontravam-se milhares de brasileira(o)s.

Apesar da pouca escolaridade, Carolina sempre foi apaixonada pelos livros. Em seu diário, ela menciona o fato de que suas(seus) vizinha(o)s diziam que ela queria ser "muita coisa" só porque não bebia pinga. Ela justifica isso por ter filha(o)s para criar, por ser uma mulher sozinha e, também, porque não gostava de beber. Diz preferir empregar seu dinheiro em livros e, ainda, pede para que a(o)s leitora(e)s que a leem, caso concordem com essa atitude, que lhe digam: "Muito bem, Carolina" (Jesus, $1960 / 2007$, p. 74). Ela lia e escrevia quando e onde dava, entre uma atividade e outra, entre um momento de angústia e outro, de súbita paz alcançada. São palavras dela: "O nervoso interior que eu sentia ausentou-se. Aproveitei a minha calma interior para eu ler. Peguei uma revista e sentei no capim, recebendo os raios solar para aquecer-me. Li um conto" (Jesus, 1960/2007, p. 12).

Escrita também feita de agenciamento (Ortner, 2008), a possibilidade de produzir interferências, de incomodar e, quiçá, magoar, é um recurso que paira no ar e que, de alguma forma, atinge a toda(o)s ao redor: "Eu percebo que se este Diário for publicado vai maguar muita gente. Tem pessoa que quando me vê passar saem da janela ou fecham as portas. Estes gestos não me ofendem" (Jesus, 1960/2007, p. 78). Além disso, fica nítido seu projeto de futuro, o agenciamento que a movimenta através do sonho de publicar seu livro, os movimentos que a escritora realiza para que o mesmo seja publicado nem que seja fora do país, a recusa em envolver-se com um homem já que não deseja atrapaIhar seus planos: "... Seu Gino veio dizer-me para eu ir no quarto dele. Que eu estou lhe despresando. DisseIhe: Não! É que eu estou escrevendo um livro, para vendê-lo. Viso com esse dinheiro comprar um terreno para eu sair da favela" (Jesus, 1960/2007, p. 28).

Estou trazendo esses trechos para destacar como a escrita de Carolina estava intimamente envolvida com o projeto maior de sair da favela, de obter reconhecimento e de ser respeitada ou temida por suas(seus) vizinha(o)s, de diferenciar-se dela(e)s, projeto que ela vai realizando entre intervalos de uma comida que cozinha, de um trabalho que realiza, do cotidiano que tem para gerenciar, de um súbito desânimo que assola sua alma e a faz fraquejar. Anzaldúa (2000) pergunta: e quem tem tempo ou energia para escrever, depois de cuidar do marido, do amante, das crianças e do trabalho fora de casa? Carolina foi a prova viva de que energia havia. Com sua língua de fogo, ela atrela sua escrita a uma luta: ir embora dali. Para tanto é necessário lembrar, tal como ilustra Ortner (2008) que, nesse caso, agência tem muito mais a ver com uma intenção, um desejo, do que com o poder simplesmente. Carolina, assim, pode ser vista como alguém que estava tentando jogar seus "jogos sérios" (Ortner, 2008), como alguém que perseguia seus objetivos incansavelmente. Mas, vale dizer, não de modo individual, já que a agência é algo que acontece numa esfera de negociações, no meio de inúmeros processos interativos. Desse modo, não existe total liberdade para jogar, uma vez que não é possível atingir metas num vazio social. Como ser social, Carolina só poderia atuar, seguindo o pensamento de Ortner (2008, p. 74), "[...] dentro de muitas teias de relações que compõem seus mundos sociais".

\section{"Falando em Línguas": Desigualdade e Marcadores Sociais das Diferenças}

A leitura da obra de Carolina permite enxergar como a desigualdade social é racializada e generificada, apontando para um rico cenário de denúncia social em que quase nada escapa. É possível ver como a pobreza (M. Santos, 2012; Silva e Silva, 2014; Yasbek, 2012) é delimitada a partir de uma posição desigual entre os sujeitos que acaba por dificultar o acesso de determinados grupos sociais a serviços públicos básicos como saúde, educação, justiça, habitação, além de restringir sua participação social e política nas decisões públicas e o acesso à redistribuição da riqueza socialmente produzida, assentando-se sobre a exploração de sua mão de obra, visível através da multiplicação de trabalhos informais, exploráveis e salários indignos. Carolina mesma diz: "O meu sonho era andar bem limpinha, usar roupas de alto preço, residir numa casa confortavel, mas não é possível. Eu não estou descontente com a profissão que exerço. Já habituei-me andar suja" (Jesus, 1960/2007, p. 22). De acordo com lanni (1989), a questão social é um tema que atravessa a sociedade brasileira desde a escravidão, na qual escrava(o)s eram exproriada(o)s do produto de seu trabalho, não dispondo de si própria(o)s, sendo propriedade de outrem. O trabalho, sua organização e os modos 
de produção que o caracterizam sempre estiveram no centro da questão social, já que os progressos da economia têm raízes na pauperização de trabalhadora(e)s. A leitura de "Quarto de despejo" permite que visualizemos o modo como diferenças costumam ser transformadas em desigualdades, hierarquizando grupos sociais. Por isso mesmo, a diferença precisa ser pensada como uma ferramenta analítica a fim de que seja possível investigar quais são os processos que marcam certos indivíduos e grupos como diferentes (Brah, 2006).

De acordo com Silva (2008), identidades e diferenças são produzidas dentro de campos de relações de força e poder. Esses campos são hierárquicos e se valem do processo de assentamentos de fronteiras para que o "eu" e o "ela(e)s" sejam construídos. Assim, a partir do momento em que faço uma afirmação (exemplo: "sou brasileira"), abro um amplo leque de negações no qual vai residir tudo aquilo que eu não sou. Silva (2008) diz que, justamente por isso, tal processo de diferenciação que produz identidades e diferenças é sempre relacional e performático. Para que eu faça afirmações como a que coloquei acima, necessito criar suas negações, o que demonstra que as identidades são construídas em relação às diferenças. Dessa forma, uma série de gestos, códigos, práticas - atos performativos - precisam existir para que um determinado grupo social possua as características que o definem como pertencente a determinadas categorias. Esse processo de assentar fronteiras visa ordenar o mundo em grupos sociais, valendo-se, para tanto, de mecanismos como os de inclusão e exclusão (eu pertenço/ela(e)s não pertencem), classificação (desenvolvida(o)s/primitiva(o)s), normalização (normais/anormais). Um exemplo disso: "... Havia pessoas que nos visitava e dizia: - Credo, para viver num lugar assim só os porcos. Isso aqui é o chiqueiro de São Paulo" (Jesus, 1960/2007, p. 36). A(o)s moradora(e) $s$ do Canindé, dessa forma, eram transformada(o)s em urubus, lixo, dejetos; enfim, eles eram coisas, o que lhes retira qualquer traço de humanidade. Esse modo de pensar justifica, ainda hoje, o isolamento e, em alguns casos, o extermínio de grupos tidos como diferentes.

O que chama a atenção nesse modo de ordenar o mundo é que procura-se excluir o caráter histórico e social que leva um grupo a ser construído do modo como o vemos. Assim, os marcadores passam a ser encarados de modo biologizado, essencializado (Corrêa, 2001). Os grupos dos "outros" são justamente aqueles que, uma vez próximos da natureza (neste caso, entendida como se fosse inferior e apartada da cultura), devem ser colonizados e domesticados para não colocarem em risco o projeto civilizatório e cultural. É interessante observar que os processos de diferenciação caracterizam-se por delimitarem de modo violento as propriedades. De acordo com Azerêdo (2011), a diferença tem justamente a ver com a delimitação daquilo que me pertence, que é só meu e que, em último caso, sou eu. A violência reside no fato de que são eliminada(o)s toda(o)s aquela(e)s que desmentem as fronteiras. É violenta porque ignora os processos históricos, sociais, econômicos e subjetivos que a(o)s constituem, demarcando-a(o)s sem considerar, assim, suas narrativas, experiências, desejos. É violenta, por fim, porque os grupos estão posicionados desigualmente e disputam o acesso privilegiado a determinados bens, materiais e simbólicos, socialmente produzidos. Logram acesso a tais bens frequentemente os grupos que detém mais poder, mais status social e econômico. Há diversas passagens na obra de Carolina Maria de Jesus que atestam sua carência em relação a esses bens, o modo como ela era impedida de desfrutar desses direitos enquanto cidadã, sobretudo no que tange à saúde, assistência social, educação, chegando até mesmo a ser presa por reivindicá-los.

De acordo com Crenshaw (2002) incorporar a discussão sobre intereseccionalidade é importante porque demonstra que algumas diferenças fazem diferença, isto é, algumas diferenças facilmente transformam-se em desigualdades e, assim, em exílio social. Outro aspecto importante dessa discussão é que quando falamos em privações econômicas, devemos sempre ter em mente que as mesmas vêm acompanhadas de privações e desrespeitos culturais (em relação à raça, gênero, etc), tal como ensina Fraser (2006) e como denuncia hooks (2015) que, em texto no qual aborda a escolarização de homens negros, denuncia o modo como estes são concebidos, socialmente, como sujeitos desprovidos de habilidades intelectuais. Sob a visão estereotipada do racismo e sexismo que os enxergam muito mais como um corpo do que como uma mente, eles são vistos na sociedade de supremacia branca, capitalista e patriarcal como sujeitos que parecem idiotas ou, então, como pessoas lentas, pouco inteligentes.

Ainda que o paradigma político do século XXI sejam as lutas por reconhecimento da diferença, é preciso não (se) esquecer que essas diferenças estão assentadas em um mundo de desigualdade social brutal. Ao lutarmos por justiça precisamos lutar conjuntamente por políticas que envolvam tanto redistribuição como reconhecimento (Fraser, 2006). Ao ler o livro de Carolina, é possível perceber que a fome é a principal protagonista dessa história: "Passei uma noite horrivel. Sonhei que eu residia numa 
casa residível.[...]. Sentei na mesa para comer [...].Eu comia bife, pão com manteiga, batata frita e salada. Quando fui pegar outro bife despertei. (Jesus, 1960/2007, p. 40). Justamente porque era pobre, ela via frequentemente vários preconceitos serem desferidos contra ela e a(o)s moradora(e)s da favela. São palavras dela: "[...] Passou um senhor, parou e nos olhou. E disse perceptível: - Será que este povo é deste mundo? Eu achei graça e respondi: Nós somos feios e mal vestidos, mas somos deste mundo" (Jesus, 1960/2007, p. 146)". Apartada de serviços básicos, ilhada na favela que frequentemente inundava e trazia doenças em função da ausência de saneamento, luz elétrica, água e de políticas públicas, a população do Canindé, vivendo da caridade de centros espíritas e do oportunismo de alguns políticos em época de eleição, sofria na pele os efeitos da privação econômica e esta, por sua vez, desdobrava-se em milhares de preconceitos contra ela.

Assim, subordinação econômica e cultural, uma vez entrelaçadas, passam a criar desafios para que as compreendamos de modo a não priorizarmos uma em detrimento da outra. Desigualdades sociais precisam ser pensadas sempre sob a perspectiva de que são racializadas e generificadas, isto é, atingem diferentemente sujeitos negra(o)s e branca(o)s, mulheres e homens. A dificuldade de Carolina ser reconhecida como uma escritora e mesmo de ter seus textos lidos demonstra como fronteiras são delimitadas em razão da cor. Diz ela: "... Eu escrevia peças e apresentava aos diretores de circos. Eles respondia-me: - É pena você ser preta" (Jesus, 1960/2007, p. 65). Apesar disso, é possível ver a questão da agência (Ortner, 2008) se sobressaindo nesse tipo de assunto, através do rompimento com o embranquecimento tão duramente encetado contra pessoas negras em nossa sociedade: "Esquecendo eles que eu adoro a minha pele negra, e o meu cabelo rustico. Eu até acho o cabelo de negro mais iducado do que o cabelo de branco. [...]. Se é que existe reincarnações, eu quero voltar sempre preta" (Jesus, 1960/2007, p. 65).

Aqui é necessário abrir um grande parênteses chamando a atenção para o que Maia (2012) diz sobre o fato de que o sujeito branco, nas discussões sobre raça e etnia, acabar figurando quase como um sujeito invisível, havendo, portanto, um verdadeiro silêncio a respeito da branquidade, como ela é constituída e o quanto colabora para que existam desigualdades raciais e sociais. Os estudos brasileiros, de acordo com essa autora, recaem sempre sobre negras e negros. Frequentemente se procura compreender a questão do racismo como um problema de mulheres e homens negra(o)s e não como um problema relacionado às(aos) branca(o)s. Bell Hooks (2013), por sua vez, lança uma provocação ao demonstrar que a maioria das mulheres brancas que escreve teorias feministas focadas na diferença e na diversidade não tomam as experiências das mulheres brancas como tema de suas análises sobre raça, focando tão somente na experiência de mulheres negras e de cor. Para ela, é urgente que mulheres brancas consigam compreender o sentido da supremacia branca para a dominação racista. Assim, ao discutir esse tema, precisamos partir do reconhecimento de nossos privilégios, caso sejamos branca(o)s, dos espaços sociais que sempre estiveram abertos em função da cor de nossa pele, das facilidades e dos poderes que estiveram o tempo todo em nossas mãos, das conivências com situações de racismo. Isso, sem dúvida, afetará nossas ações enquanto profissionais, pois, muitas vezes, acabamos esquecendo-nos que raça é um fator que exclui milhares de brasileira(o)s, e nos concentramos apenas nas discussões sobre desigualdade social.

O mesmo exercício deve ser realizado quando o assunto é gênero, pois de acordo com Matos e Paradis (2014), o Estado brasileiro é constituído, historicamente, como patriarcal e racista. Mulheres são relegadas à esfera doméstica, apartadas da produção social, sem possibilidades de participação no cenário político e, portanto, de tomada decisões. O trabalho realizado por homens é o único que possui relevância e atualmente o patriarcado pode ser definido como uma espécie de organização social no qual as relações são regidas por dois princípios: o primeiro coloca as mulheres hierarquicamente subordinadas aos homens e, o segundo, coloca $\mathrm{a}(\mathrm{o}) \mathrm{s}$ jovens subordinada(o)s às(aos) mais velha(o)s. A invisibilidade dessa participação é percebida em trecho escrito por Carolina Maria de Jesus em 1958: "...Quando eu era menina o meu sonho era ser homem para defender o Brasil porque eu lia a Historia do Brasil e ficava sabendo que existia guerra. Só lia os nomes masculinos como defensor da patria" (Jesus, 1960/2007, p. 54-55).

Essas são algumas amostras de um exercício maior que tem, em última instância, o objetivo de mostrar a necessidade de que a formação em psicologia parta do território existencial das populações com as quais trabalha para pensar suas intervenções. A obra de Carolina, passados mais de cinquenta anos de sua publicação, permanece extremamente atual, seja porque permite que compreendamos as passagens históricas e os ganhos advindos de várias reivindicações e conquistas (como por exemplo, a adoção de um sistema de saúde universal e gratuito, algo que a escritora não 
conheceu), seja porque permite que nos debrucemos sobre seu território para compreendermos as conexões entre as várias opressões vivenciadas por essa personagem nada fictícia. Dimenstein e Macedo (2012) falando sobre a atuação da psicologia na atenção primária e psicossocial chamam a atenção para o fato de que a intervenção psicossocial deve levar em conta o território daquela(e)s que serão acompanhada(o)s. Isto é, é preciso conhecer a história do território, seus aspectos geofísicos, estruturais, sociopolíticos, além das necessidades daquela(e)s que ali habitam.

\section{Conclusão}

Nesse texto tentei fazer um convite para alunas e alunos embarcarem no território de vida de Carolina Maria de Jesus. Junto dela, será possível passar por discussões que abarquem políticas públicas e sociais, direitos humanos, marcadores sociais das diferenças, poder, trabalho precário, dentre outras, de modo que seja possível criar ensaios de ação e visualizar os limites e potencialidades da atuação $p s i$ em diferentes campos de atuação, tomando como pressuposto que é justamente a narrativa das pessoas com as quais trabalhamos que permite a indicação de caminhos para nossa intervenção. Nesse sentido, Gonçalves Filho (2003) elucida bem como o sofrimento oriundo da espoliação econômica, do racismo, da segregação, da dominação, da pobreza, dentre tantos outros, não torna idêntico suas(seus) sofredora(e)s, já que cada pessoa exposta à humilhação pública, tem uma maneira singular de sofrer e reagir que lhe é própria. Com isso, seguir a indicação desse autor é um bom início: quem desejar atinar com a dor dessa(e)s cidadã(o)s, precisa demorar-se entre ela(e)s, precisa repetir e prolongar suas visitas, vê-la(o)s e ouvi-la(o)s de perto.

\section{Referências}

Antunes, M. A. M. (2012). A Psicologia no Brasil: um ensaio sobre suas contradições. Psicologia: Ciência e Profissão, 32, 44-65. doi: 10.1590/S1414- 98932012000500005

Anzaldúa, G. (2000). Falando em línguas: uma carta para as mulheres escritoras do terceiro mundo. Revista Estudos Feministas, 229-236. Recuperado de https://periodicos.ufsc.br/index.php/ref/article/ view/9880/9106

Azerêdo, S. M. da M. (2003). Era uma vez... uma análise. Cadernos Pagu, 20, 205-216. doi: 10.1590/S0104-83332003000100008

Azerêdo, S. M. da M. (2011). Preconceito contra a mulher: diferença, poemas e corpos. São Paulo: Cortez.

Brah, A. (2006). Diferença, diversidade, diferenciação. Cadernos Pagu (26), 329-376. doi: 10.1590/S0104-83332006000100014
Cardoso, C. P. (2014). Amefricanizando o feminismo: o pensamento de Lélia Gonzalez. Estudos Feministas, 22(3), 965-986. doi: 10.1590/ S0104-026X2014000300015

Carrillo, J. (2010). Entrevista com Beatriz Preciado. Revista Poiésis, 15, 47-71. doi: 10.1590/S0104-83332007000100016

Castro, E. M., \& Matta, M. N. M. (2007). Muito bem, Carolina! Biografia de Carolina Maria de Jesus. Belo Horizonte: C/Arte.

Coimbra, M. C. R. (2007). Afirmando as multiplicidades. In N Guareschi \& S. Hüning (Orgs.), Implicações da psicologia no contemporâneo (pp. 9-11). Porto Alegre: EDIPUCRS.

Corrêa, M. (2001). Do feminismo aos estudos de gênero no Brasil: um exemplo pessoal. Cadernos Pagu, 16, 13-30. doi: 10.1590/ S0104-83332001000100002

Crenshaw, K. (2002). Documento para o encontro de especialistas em aspecto da discriminação racial relativos ao gênero. Revista Estudos Feministas, 10(1), 171-188. doi: 10.1590/ S0104-026X2002000100011

Cruz, J. M. O. (2009). Práticas psicológicas em Centro de Referência da Assistência Social. Psicologia em Foco, 2, 11-27. Recuperado de http://periodicos.piodecimo.edu.br/online/index.php/ psicologioemfoco/article/view/26

Dimenstein, M. (2000). A cultura profissional do psicólogo e o ideário individualista: implicações para a prática no campo da assistência pública à saúde. Estudos de Psicologia, 5(1), 95-121. doi: 10.1590/ S1413-294X2000000100006

Dimenstein, M., \& Macedo, J. P. (2012). Formação em Psicologia: requisitos para a atuação na atenção primária e psicossocial Psicologia: Ciência e Profissão, 32, 232- 245. doi: 10.1590/ S1413-294X2000000100006

Fraser, N. (2006). Da redistribuição ao reconhecimento? Dilemas da justiça numa era "pós-socialista". Cadernos de Campo, 15(14/15), 231-239. doi: 10.11606/issn.2316-9133.v15i14-15p231-239

Freitas, M. F. Q. (2015). Práxis e formação em psicologia social comunitária. Estudos de Psicologia, 32(3), 521-532. doi: 10.1590/0103-166X2015000300017

Gonçalves Filho, J. M. (2004). Problemas de método em Psicologia Social: algumas notas sobre a humilhação política e o pesquisador participante. In A. M. B. Bock (Org.), Psicologia e compromisso social (pp. 193-240). São Paulo: Cortez Editora.

Gonçalves, M. A. (2014). Um mundo feito de papel: sofrimento e estetização da vida (os diários de Carolina Maria de Jesus). Horizontes Antropológicos, 20, 24, 21-47. doi: 10.1590/ s0104-71832014000200002

Gonzales, L. (1984). Racismo e sexismo na cultura brasileira. Revista Ciências Sociais Hoje, (Anpocs), 223-244.

Grosfoguel, R. (2016). A estrutura do conhecimento nas universidades ocidentalizadas: racismo/sexismo epistêmico e os quatro genocídios/epistemicídios do longo século XVI. Sociedade e Estado, 31(1), 25-49. doi: 10.1590/S0102-69922016000100003

Hanada, H.; D’Oliveira, A. F. P. L., \& Schraiber, L. B. (2010). Os psicólogos na rede de assistência a mulheres em situação de violência. Revista Estudos Feministas, 18(1), 33-59. doi: 10.1590/ S0104-026X2010000100003

Haraway, D. (2004). 'Gênero' para um dicionário marxista: a política sexual de uma palavra. Cadernos Pagu, 22, 201-246. doi: 10.1590/ S0104-83332004000100009

Hooks, B. (2013). Ensinando a transgredir: a educação como prática da liberdade. São Paulo: WMF Martins Fontes. 
Uma "monstra perigosa": Pistas de Carolina Maria de Jesus para a intervenção psicossocial

Hooks, B. (2015). Escolarizando homens negros. Revista Estudos Feministas, 23(3), 677-689, 2015. doi: 10.1590/0104-026X2015v23n3p677

Ianni, O. (1989). A questão social. Revista da USP, 145-154. doi: 10.11606/issn.2316-9036.v0i3p145-154

Jacó-Vilela, A. M. (2007). O estatuto da psicologia social: contribuições da história da psicologia social. In C. Mayorga \& M. A. P. Prado (Orgs.), Psicologia social: articulando saberes e fazeres (pp. 37-54). Belo Horizonte: Autêntica.

Jesus, C. M. (2007). Quarto de despejo: diário de uma favelada. São Paulo: Ática. (Obra original publicada em 1960)

Maia, S.(2012). Identificando a branquidade inominada: corpo, raça e nação nas representações sobre Gisele Bündchen na mídia transnacional. Cadernos Pagu, 38, 309-341. doi: 10.1590/ S0104-83332012000100011

Maluf, S. W., \& Costa, C. L. (2001). Feminismo fora do centro: entrevista com Ella Shohat. Revista Estudos Feministas, 9(1), 147-163. doi: 10.1590/S0104-026X2001000100008

Matos, M., \& Paradis, C. G. (2014). Desafios à despartriarcalização do Estado brasileiro. Cadernos Pagu, 43, 57-118. doi: 10.1590/0104-8333201400430057

Mayorga, C. (2014). Algumas contribuições do feminismo à psicologia social. Athenea Digital, 14(1), 221-236. Recuperado de http://www. redalyc. org/articulo. oa? id $=53730481010$

Meihy, J. C. S. B. (2016). Repensando Carolina Maria de Jesus. Revista Diversitas, 3, 520-529. Recuperado de https://www.revistas.usp.br/ diversitas/article/view/113905

Montero, M. (2006). La comunidad como ámbito de ciudadanía: carácter político del trabajo psicosocial comunitário. In M. Montero (Org.), Teoría y práctica de la psicología comunitaria : la tensión entre comunidad y sociedade (pp. 143-171). Buenos Aires: Paidós.

Montero, M. (2015). De la otredad a la praxis liberadora: la construcción de métodos para la conciencia. Estudos de Psicologia, 32(1), 141-149. doi: 10.1590/0103-166X2015000100013

Ortner, S. B. (2008). Poder e projetos: reflexões sobre a agência. In M. P. Grossi; C. Eckert; \& P. H. Fry (Orgs.), Conferências e práticas antropológicas: textos de Bárbara Glowezewski... (et. alli) (pp. 45-80). Blumenau: Nova Letra.
Pelúcio, L. (2012). Subalterno quem, cara pálida? Apontamentos às margens sobre pós-colonialismos, feminismos e estudos queer. Contemporânea, 2(2), 395-418. Recuperado de http://www. contemporanea.ufscar.br/index.php/contemporanea/article/ view/89/54

Pinheiro, J., \& Barbosa, S. (2016). Carolina. São Paulo: Veneta.

Querido, A. M. (2012). Autobiografia e autorretrato: cores e dores de Carolina Maria de Jesus e de Frida Kahlo. Estudos Feministas, 20(3), 881-899. doi: 10.1590/S0104-026X2012000300016

Santos, J. R. (2009). Carolina Maria de Jesus: uma escritora improvável. Rio de Janeiro: Garamond.

Santos, M. (2012). Por uma outra globalização. Rio de Janeiro/São Paulo: Record.

Schraiber, L. (2012). Necessidades de saúde, políticas públicas e gênero: a perspectiva das práticas profissionais. Ciência \& Saúde Coletiva, 17(10), 2635-2644. doi: 10.1590/ S1413-81232012001000013

Silva, T. T. (2007). A produção social da identidade e da diferença. In T. T. Silva (Org.), Identidade e diferença: a perspectiva dos Estudos Culturais (pp.73-102). Petrópolis: Vozes.

Silva e Silva, M. O. (2014). Panorama geral dos programas de transferência de renda na América Latina e Caribe. Revista de Políticas Públicas, (num. espec.), 299-306. doi: 10.18764/2178-2865. v18nEp299-306

Sousa, G. H. P. (2011). Memória, autobiografia e diário íntimo. Carolina Maria de Jesus: escrita íntima e narrativa da vida. In $\mathrm{H}$. Bastos \& A. B. Araújo (Orgs), Teoria e prática da crítica literária dialética (pp. 86-108). Brasília: Editora Universidade de Brasília.

Stralen, C. J. (2005). Psicologia social: uma especialidade da psicologia? Psicologia \& Sociedade, 17(1), 17-28. doi: 10.1590/ S0102-71822005000100015

Yamamoto, O. H., \& Oliveira, I. F. (2010). Política social e psicologia: uma trajetória de 25 anos. Psicologia: Teoria e Pesquisa, 26, 9-24. doi: 10.1590/S0102-37722010000500002

Yasbek, M. C. (2012). Pobreza no Brasil contemporâneo e formas de seu enfrentamento. Serviço Social \& Sociedade, 110, 288-322. doi: $10.1590 / \mathrm{S} 0101-66282012000200005$

1. Para discussão um pouco mais detalhadas sobre escritora(e)s que venho utilizando em sala de aula, sugiro a leitura do artigo (informação suprimida em função do parecer cego).

2. A data do nascimento de Carolina é incerta. De acordo com Castro e Machado (2007), não se sabe ao certo se Carolina nasceu em 1913 , 1914 ou 1915.

3. Gonçalves (2016) refere-se a 140 cadernos.

Érika Cecilia Soares Oliveira, Doutora em Psicologia/Área: Psicologia e Sociedade pela Universidade Estadual Paulista "Júlio de Mesquita Filho", campus de Assis/São Paulo, é Professora Adjunta da Universidade Federal de Alagoas/UFAL (campus de Maceió). Endereço para correspondência: Universidade Federal de Alagoas - Instituto de

Psicologia, Av. Lourival Melo Mota, $\mathrm{s} / \mathrm{n}$, Tabuleiro do Martins, CEP: 57072-900, Maceió - AL. E-mail: erika.oliveira@ip.ufal.br 